\title{
Trace element heterogeneities of in-situ diamond inclusion garnets from Siberia.
}

\author{
N. Shimizu1 ${ }^{1}$ N. V. Sobolev², and E. S. Yefimova 2
}

1: Department of Marine Geology and Geophysics, Woods Hole Oceanographic Institution, 360 Wood Hole Rd, Woods Hole, MA 02540-1541, USA

2: United Institute for Geophysics and Mineralogy, Russian Acad. Sci., Novosibirsk

A question has been raised for trace element abundances of garnet inclusions in diamonds reported by Shimizu and Sobolev (1995) and Shimizu et al. (1997), as garnets were liberated by burning host diamonds, which might have contributed to highly heterogeneous distribution of elements. Since chemical heterogeneities were used as strong evidence for young formation ages of diamonds, it is important to demonstrate that chemical heterogeneity is not resulted from burning.

We report here results of trace element analyses of peridotitic garnet inclusions exposed insitu in host diamonds.

Analytical techniques used here are identical to those used in previous studies (e.g., Shimizu et al., 1997); a Cameca IMS $3 \mathrm{f}$ ion probe at Woods Hole Oceanographic Institution was operated with an energy offset of $-90 \mathrm{~V}$ for $\mathrm{Ti}, \mathrm{V}, \mathrm{Sr}, \mathrm{Y}$, and $\mathrm{Zr}$, and $-60 \mathrm{~V}$ for rare earth elements. A spatial resolution of approximately $5 \mu \mathrm{m}$ was used. Samples studied are from Mir, Udachnaya and Aikhal kimberlite pipes.

Since host diamond prevents further grinding and polishing of garnet after an analytical session, chances for exposing a high-Sr corner (e.g., Shimizu et al., 1997) are considerably lower than liberated grains. In addition, most grains analyzed here had pieces broken off during sample preparation, which further decreases chances for complete documentation of chemical heterogeneities.

At the time of writing, 10 in-situ grains were analyzed on more than 5 spots. 6 of these grains were found to have at least one element varying more than a factor of 2 . 2 grains showed $\mathrm{Sr}$ variations by more than a factor of 10 . Sr showed the largest overall variability in frequency and range, but in some grains $\mathrm{Y}$ or $\mathrm{Zr}$ was the most variable. The most spectacular was Ud-5 (Udachnaya); Sr variation was similar to MR 129/15 (Mir) described previously (Shimizu and Sobolev, 1995), with Sr ranging from 313 to $5.0 \mathrm{ppm}$, Y by a factor of 4, and Zr, in contrast, by only $45 \%$. The high-Sr corner of the grain possesses a smoothly LREE-enriched pattern with [La]n $=160,[\mathrm{Ce}]_{\mathrm{n}}=140,[\mathrm{Dy}]_{\mathrm{n}}=3.8 .[\mathrm{Yb}]_{\mathrm{n}}=2.2$. The center of the grain $(\mathrm{Sr}=5.0 \mathrm{ppm})$ has a sinusoidal pattern with $[\mathrm{La}]_{\mathrm{n}}=0.6,[\mathrm{Nd}]_{\mathrm{n}}=11 .[\mathrm{Dy}]_{\mathrm{n}}=1.5,[\mathrm{Yb}]_{\mathrm{n}}=2.1$.

Although the number of grains examined is not large the results clearly demonstrate that chemical heterogeneities in in-situ garnets are comparable to burn-liberated counterparts in frequency and concentration range. It is concluded therefore that the results reported previously are not an artifact derived from burning diamonds.

\section{References.}

Shimizu, N. and Sobolev, N. V., 1995, Young peridotitic diamonds from the Mir kimberlite pipe, Nature, 375, p.394-397.

Shimizu, N., Sobolev, N. V., and Yefimova, E. S., 1997, Chemical heterogeneities of inclusion garnets and juvenile character of peridotitic diamonds from Siberia, Russ. Geol. Geophys., 38, p. 356-372. 